\title{
Grape Maturity and Wine Quality
}

\author{
C. S. DU PLESSIS AND P. C. VAN ROOYEN \\ Oenological and Viticulture Research Institute, Private Bag X5026, Stellenbosch, 7600
}

Submitted for publication: June 1982

Accepted for publication: September 1982

\begin{abstract}
Several indices calculated from grape juice analyses were submitted to statistical analyses in order to determine correlations of these indices with quality of wine made from grapes at different stages of maturity. Curvilinear relationships were obtained enabling an optimum point to be calculated relating grape maturity to maximum wine quality. The application of skin contact in the case of white wine cultivars resulted in earlier maxima for wine quality, thus compensating to an extent for earlier harvesting. The cultivars Chenin blanc, Colombar, Pinotage and Cabernet Sauvignon were examined as outlined above over several years.
\end{abstract}

The stage of grape maturity has a marked effect on wine quality (Ough \& Singleton, 1968; Ough \& Alley, 1970; du Plessis, 1975), and optima in this regard have been studied extensively and have been the subject of many scientific publications (Amerine \& Winkler, 1941; Berg, 1958, Reutlinger, 1973; Kourakou, 1974; Sinton, Ough, Kissler \& Kasimatis, 1978; Coombe, Dundon \& Short, 1980). In these studies special attention was paid to the use of ratios of readily determinable grape components in order to define optimum wine grape maturity. The use of single parameters such as ${ }^{\circ}$ Brix or acidity has not been very successful in this regard (Berg, 1958; du Plessis, 1976; Coombe et al., 1980). Total soluble solids $\left({ }^{\circ} \mathrm{B}\right)$ has been used in South Africa for a considerable time as an index for optimum maturity in grapes, but without much success, because other equally important factors are not taken into account. It is important that more precise, reliable and applicable maturity parameters be found to improve or replace those currently in use.

\section{MATERIALS AND METHODS}

Grape samples and vinification procedures: Four wine grape cultivars viz. Chenin blanc (Stellenbosch area), Colombar, (Robertson area), Pinotage (Stellenbosch area) and Cabernet Sauvignon (Stellenbosch area) were studied. Specific vineyards were selected for each cultivar and sampled for at least three successive years. Harvesting was done from early maturity i.e. about $19^{\circ} \mathrm{B}$ to as late as possible at approximately weekly intervals. Representative harvests were taken; e.g. should six harvests be taken, then every seventh vine in the vineyard would be harvested at each harvesting of not less than 45 vines.

Free run (FR) juice as well as juice obtained after skin contact (SC) treatments were used for white wines. In order to limit bias as far as possible, grapes from a randomly chosen side of the vine were used for FR and grapes from the other for SC juice. For the latter treatment the mash was held at approximately $20^{\circ} \mathrm{C}$ for 4 hours prior to drawing off the juice. The $\mathrm{SC}$ and $\mathrm{FR}$ juices were settled overnight at $c .4^{\circ} \mathrm{C}$ at a total $\mathrm{SO}_{2}$ concentration of approximately $75 \mathrm{mg} / \ell$. The settled juice was divided into two lots and fermented separately at $15^{\circ} \mathrm{C}$ after inoculation with a $3 \%$ pure yeast culutre. (Saccharomyces cerevisiae, strain WE 14, OVRI collection).

The red cultivars were fermented on their skins after inoculation with a $3 \%$ yeast culture (WE 14) at similar $\mathrm{SO}_{2}$ levels as noted above. Fermentation proceeded with punching through three times per day until a decrease of $10^{\circ} \mathrm{B}$ had been achieved. Subsequently the must was drawn off, divided into two lots and fermented dry at $20^{\circ} \mathrm{C}$. Prior to bottling all $\mathrm{SO}_{2}$ levels were adjusted to $c$. $25 \mathrm{mg} / \ell$ free $\mathrm{SO}_{2}$.

Must analysis: Total acidity was determined on centrifuged juice samples $(750 \mathrm{~g} \mathrm{x} 5 \mathrm{~min})$ of FR and SC treatments by titrating to $\mathrm{pH} 8,2$ with $c .0,1 \mathrm{~N} \mathrm{NaOH}$ solution. Total soluble solids were determined on the centrifuged sample by refractometer and corrected for grape sugars as reported by Cooke (1964).

Sensory evaluation: Overall wine quality was evaluated by a panel of $15-20$ using the system described by Tromp \& Conradie (1979), and expressed as a percentage.

Data processing: Second degree polynomials were fitted to sensory evaluation scores, and simple and multiple correlation coefficients calculated.

The total acidity (TA), ${ }^{\circ} \mathrm{B}, \mathrm{pH}$ and hydrogen ion concentration $(\mathrm{H})$ were used to calculate seventeen two-component and three-component indices (Table 1) which were then related to wine quality. The sensory evaluation data of FR and SC wines were correlated to FR juice analyses since it would be impractical for a wine maker to wait for 4 hours before analyzing SC samples.

TABLE 1

Grape juice component indices calculated for correlation with wine quality data

\begin{tabular}{llll}
\hline Number & Index & Number & Index \\
\hline 1 & ${ }^{\circ} \mathrm{B} / \mathrm{H}$ & 10 & TA.pH \\
2 & ${ }^{\circ} \mathrm{B} / \mathrm{pH}$ & 11 & ${ }^{\circ} \mathrm{B} . \mathrm{TA} / \mathrm{H}$ \\
3 & ${ }^{\circ} \mathrm{B} . \mathrm{pH}$ & 12 & ${ }^{\circ} \mathrm{B} . \mathrm{TA} / \mathrm{pH}$ \\
4 & ${ }^{\circ} \mathrm{B} . \mathrm{H}$ & 13 & ${ }^{\circ} \mathrm{B} . \mathrm{H} / \mathrm{TA}$ \\
5 & ${ }^{\circ} \mathrm{B}+\mathrm{TA}$ & 14 & ${ }^{\circ} \mathrm{B} . \mathrm{pH} / \mathrm{TA}$ \\
6 & ${ }^{\circ} \mathrm{B} . \mathrm{TA}$ & 15 & ${ }^{\circ}$ B/TA.H \\
7 & $\mathrm{TA} / \mathrm{pH}$ & 16 & ${ }^{\circ} \mathrm{B} / \mathrm{TA} \cdot \mathrm{pH}$ \\
8 & ${ }^{\circ} \mathrm{B} / \mathrm{TA}$ & 17 & \\
9 & $\mathrm{TA} . \mathrm{H}$ & & \\
\hline
\end{tabular}

${ }^{\circ} \mathrm{B}:{ }^{\circ}$ Balling

TA: Total titratable acidity $(\mathrm{g} / \ell)$

$\mathrm{H}$ : Hydrogen ion concentration $(\mathrm{mg} / \ell)$

\section{RESULTS AND DISCUSSION}

Multiple correlation coefficients giving acceptable probability levels were obtained for seven of the indices studied (See Table 1) and the F-values set out in Table 2. Although it has been reported that the ${ }^{\circ} \mathrm{B} .(\mathrm{pH})^{2}$ index has advantages over ${ }^{\circ}$ B.pH (Coombe et al., 1980), no confirmation of this could be found in this study. 
TABLE 2

F-values for 2nd degree polynomials fitting grape analysis indices to wine quality for four wine cultivars over six seasons.

\begin{tabular}{lrrrrrl}
\hline & \multicolumn{2}{c}{ Chenin blanc } & Colombard & Pinotage & $\begin{array}{l}\text { Cabernet } \\
\text { Sauvignon }\end{array}$ \\
\cline { 2 - 7 } $\begin{array}{l}\text { Maturity } \\
\text { index }\end{array}$ & $\begin{array}{c}\text { FR } \\
(\mathrm{n}=33)\end{array}$ & $\begin{array}{c}\mathrm{SC} \\
(\mathrm{n}=22)\end{array}$ & $\begin{array}{c}\mathrm{FR} \\
(\mathrm{n}=33)\end{array}$ & $\begin{array}{c}\mathrm{SC} \\
(\mathrm{n}=28)\end{array}$ & $(\mathrm{n}=34)$ & $(\mathrm{n}=26)$ \\
\hline${ }^{\circ} \mathrm{B} / \mathrm{pH}$ & $9,5^{* *}$ & $0,3 \mathrm{~ns}$ & $2,8 \mathrm{~ns}$ & $0,2 \mathrm{~ns}$ & $19,7^{* *}$ & $2,1 \mathrm{~ns}$ \\
${ }^{\circ} \mathrm{B} . \mathrm{pH}$ & $9,9^{* *}$ & $1,9 \mathrm{~ns}$ & $3,5^{*}$ & $0,3 \mathrm{~ns}$ & $16,0^{* *}$ & $5,3^{*}$ \\
${ }^{\circ} \mathrm{B} / \mathrm{TA}$ & $15,7^{* *}$ & $3,1 \mathrm{~ns}$ & $3,5^{*}$ & $0,3 \mathrm{~ns}$ & $19,5^{* *}$ & $6,1^{* *}$ \\
TA/pH & $10,1^{* *}$ & $4,0 \mathrm{~ns}$ & $2,3 \mathrm{~ns}$ & $0,4 \mathrm{~ns}$ & $9,6^{* *}$ & $7,5^{* *}$ \\
TA.pH & $8,3^{* *}$ & - & $1,0 \mathrm{~ns}$ & $0,1 \mathrm{~ns}$ & $7,6^{* *}$ & $6,9^{* *}$ \\
${ }^{\circ} \mathrm{B} . \mathrm{pH} / \mathrm{TA}$ & $14,9^{* *}$ & - & $4,7^{*}$ & - & $21,0^{* *}$ & $6,2^{* *}$ \\
${ }^{\circ}$ B/TA.pH & $15,8^{* *}$ & - & $2,0 \mathrm{~ns}$ & - & $16,1^{* *}$ & $6,0^{* *}$ \\
\hline
\end{tabular}

*, **: Significant at 95 percent and 99 percent confidence levels, respectively

${ }^{\circ} \mathrm{B}$ : Degrees Balling

TA: Total titratable acidity $(\mathrm{g} / \ell)$

FR: Free run treatment

SC: Skin contact treatment

$\mathrm{n}$ : Number of samples

ns: Not significant

From Table 2 it will be seen that the two most commonly reported indices viz. ${ }^{\circ} \mathrm{B} . \mathrm{pH}$ and ${ }^{\circ} \mathrm{B} / \mathrm{TA}$ give largely similar results. Futhermore, correlation between these two indices was very highly significant. Consequently, discussion will be limited to one index, viz. ${ }^{\circ} \mathrm{B} / \mathrm{TA}$. The three component index ${ }^{\circ} \mathrm{B} . \mathrm{pH} / \mathrm{TA}$ also gave results comparable to ${ }^{\circ} \mathrm{B} / \mathrm{TA}$. However, it is slightly more complicated to compute and requires one more analysis than does the ${ }^{\circ} \mathrm{B} / \mathrm{TA}$ index.

White Cultivars: $F R$ treatment: The index values at which the highest wine quality was obtained are given in Table 3.

TABLE 3

Maturity index values at maximum quality for four wine cultivars over six seasons.

\begin{tabular}{lrrrrrr}
\hline & \multicolumn{2}{c}{ Chenin blanc } & \multicolumn{2}{c}{ Colombar } & Pinotage & $\begin{array}{c}\text { Cabernet } \\
\text { Sauvignon }\end{array}$ \\
\cline { 2 - 5 } $\begin{array}{l}\text { Maturity } \\
\text { index }\end{array}$ & FR & SC & FR & SC & & \\
\hline${ }^{\circ}$ B/pH & 7,02 & - & 6,44 & - & 7,05 & - \\
${ }^{\circ}$ B.pH & 73,35 & - & 64,67 & - & 92,03 & 82,97 \\
${ }^{\circ}$ B/TA & 2,78 & 2,35 & 2,31 & - & 3,88 & 3,94 \\
TA/pH & 2,71 & 3,25 & 2,79 & - & 1,59 & 1,65 \\
TA.pH & 28,01 & 31,68 & - & - & 20,20 & 20,24 \\
\hline
\end{tabular}

FR: Free run treatment

SC: Skin contact treatment

${ }^{\circ} \mathrm{B}$ : ${ }^{\circ}$ Balling

TA: Total titratable acidity $(\mathrm{g} / \ell)$

Relevant statistical data for individual years are given in Table 4. These data illustrate the effect of factors which are in all probability environmental, on the curvilinear fits of ${ }^{\circ} \mathrm{B} / \mathrm{TA}$ values to the wine quality data at different stages of grape maturity.
TABLE 4

Statistical parameters for curvilinear fits of ${ }^{\circ} \mathrm{B} / \mathrm{TA}$ indices to wine quality over several years.

\begin{tabular}{|c|c|c|c|c|c|c|c|}
\hline \multirow[t]{2}{*}{$\begin{array}{l}\text { Cultivar } \\
\text { Vintage }\end{array}$} & \multicolumn{2}{|c|}{$\begin{array}{c}\text { Multiple } \\
\text { correlation } \\
\text { coefficient }(\mathrm{R})\end{array}$} & \multicolumn{2}{|c|}{ F-value } & \multirow[t]{2}{*}{$\mathrm{n}$} & \multicolumn{2}{|c|}{ Probability } \\
\hline & FR & SC & FR & SC & & FR & $\mathrm{SC}$ \\
\hline \multicolumn{8}{|c|}{ Chenin blanc } \\
\hline 1974 & 0,98 & - & 21,6 & - & 5 & $<0,005$ & - \\
\hline 1976 & 0,97 & 0,94 & 15,2 & 7,9 & 5 & $<0,005$ & $<0,005$ \\
\hline 1977 & 0,97 & 0,74 & 38,1 & 2,4 & 7 & $<0,005$ & 0,100 \\
\hline 1978 & 0,89 & 0,66 & 5,5 & 1,1 & 6 & 0,025 & ns \\
\hline 1979 & 0,97 & 0,56 & 7,8 & 0,2 & 4 & 0,010 & ns \\
\hline 1980 & 0,72 & 0,84 & 1,6 & 3,5 & 6 & $<0,250$ & 0,05 \\
\hline \multicolumn{8}{|c|}{ Colombar } \\
\hline 1975 & 0,97 & 0,17 & 22,4 & 0,3 & 6 & $<0,005$ & ns \\
\hline 1976 & 0,83 & 0,02 & 4,5 & 0 & 7 & 0,01 & ns \\
\hline 1977 & 0,89 & 0,83 & 7,9 & 9,9 & 7 & $<0,005$ & $<0,005$ \\
\hline 1978 & 0,57 & 0,07 & 0,7 & 0,1 & 6 & ns & ns \\
\hline 1979 & 0,88 & - & 3,3 & - & 5 & 0,05 & - \\
\hline 1980 & 0,23 & - & 0,1 & - & 6 & ns & - \\
\hline \multicolumn{8}{|l|}{ Pinotage } \\
\hline 1976 & 0,99 & - & 66,3 & - & 6 & $<0,005$ & - \\
\hline 1977 & 0,93 & - & 9,2 & - & 6 & $<0,005$ & - \\
\hline 1978 & 0,95 & - & 15,2 & - & 6 & $<0,005$ & - \\
\hline 1979 & 0,94 & - & 11,3 & - & 6 & $<0,005$ & - \\
\hline 1980 & 0,58 & - & 0,8 & - & 6 & ns & - \\
\hline \multicolumn{8}{|c|}{ Cabernet } \\
\hline \multicolumn{8}{|c|}{ Sauvignon } \\
\hline 1976 & 0,93 & - & 8,2 & - & 6 & $<0,005$ & - \\
\hline 1977 & 0,92 & - & 2,7 & - & 4 & 0,100 & - \\
\hline 1978 & 0,53 & - & 0,4 & - & 5 & ns & - \\
\hline 1979 & 0,95 & - & 9,5 & - & 5 & $<0,005$ & - \\
\hline 1980 & 0,88 & - & 5,0 & - & 6 & $<0,025$ & - \\
\hline
\end{tabular}

SC: Skin contact treatment

FR: Free run treatment

$\mathrm{n}$ : Number of wines

ns : Not significant

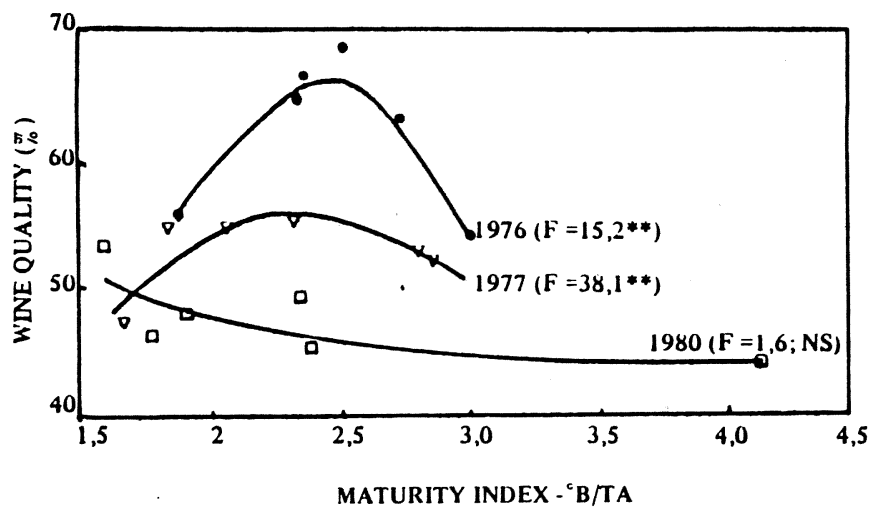

Fig. 1

Fitted curves and observed data for Chenin blanc for three years relating wine quality and grape maturity $\left({ }^{\circ} \mathrm{B} / \mathrm{TA}\right)$.

Variations which occur as a result of vintage effects are illustrated by a Chenin blanc FR sample in Fig. 1. Data for three years are given which illustrate typical results for a year with a clear maximum (1976), one where little change occurs (1977) and an example of a non-significant fit (1980). 
Good fits were obtained for all the cultivars when all the data were grouped (Table 2). However, from the data in Table 4 it may be seen that Chenin blanc data showed much better fits than did those of Colombar. The changes in total acidity and $\mathrm{pH}$ of the dry-land cultivated Chenin blanc grapes were generally relatively steady as opposed to that of the irrigated Colombar. It is quite possible that the differences in the water stress between these two vineyards could have contributed to this phenomenon. Fluctuations in $\mathrm{pH}$ and total acidity for ripening Colombar grapes are shown in Fig. 2.

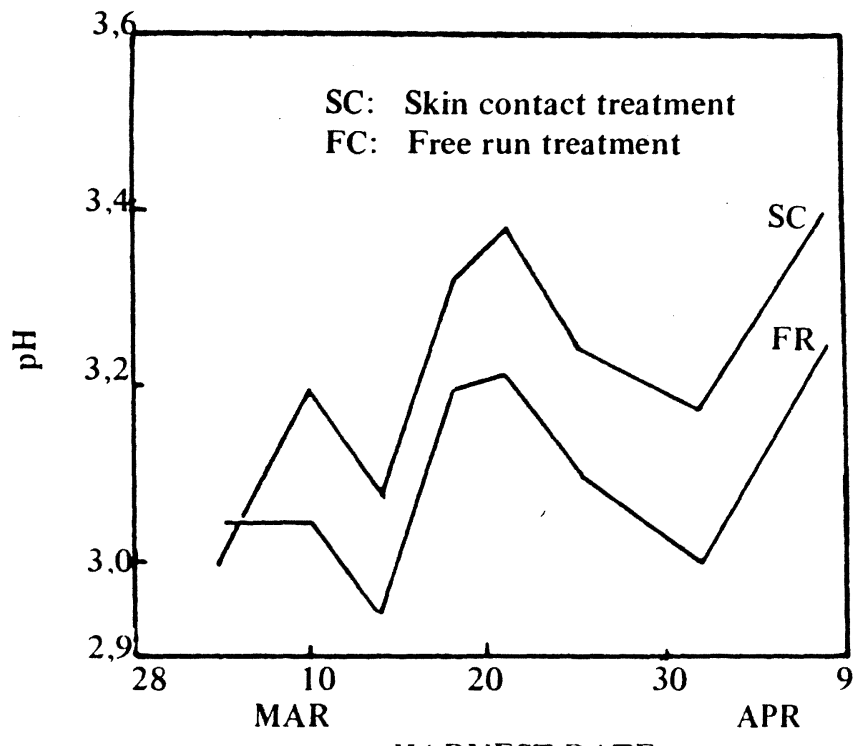

HARVEST DATE

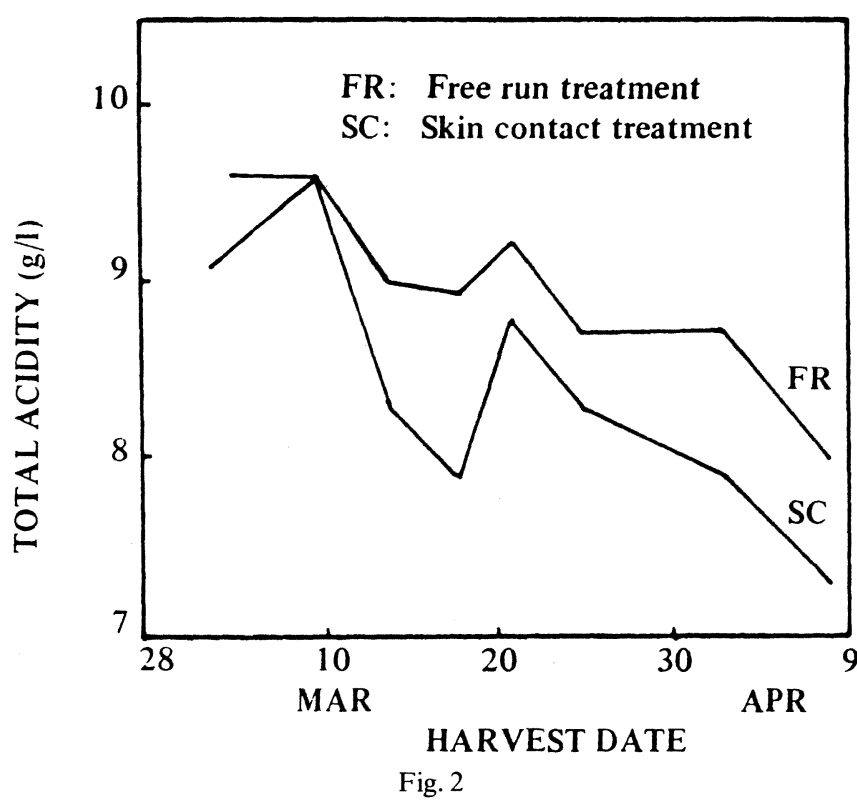

Variations of $\mathrm{pH}$ and total acidity in ripening Colombar grapes.

$S C$ treatment: Relevant results are given in Tables 2, 3 and 4. This treatment increased $\mathrm{pH}$ and decreased total acidity of the juice significantly (du Plessis, 1977). The marked effect of SC as opposed to FR on juice composition is illustrated for Colombar grapès in Fig. 2.

A most important quality aspect of ripening grapes is its acidity and the effect it has on the taste of the wine. In Colombar and up to the point of optimum grape maturity for SC wines, the acid taste was very significantly im-

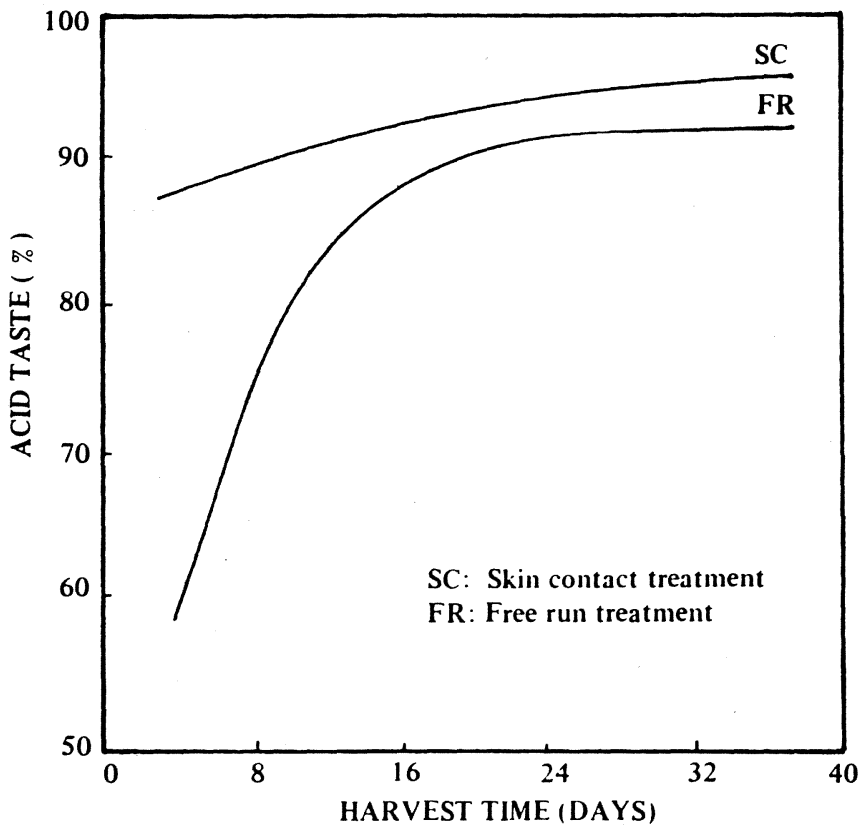

Fig. 3

The acceptability of acid taste of the wines of periodically harvested Colombar grapes of which the juice had received free run and skin contact treatments. The higher the acid taste rating the more pleasant the taste.

proved by SC in comparison with FC treatment (du Plessis, 1977) (Fig. 3). In contrast, the Chenin blanc showed no similar improvement in the acid taste although there were significant decreases and increases of total acidity and $\mathrm{pH}$ respectively by $\mathrm{SC}$ treatment.

With respect to the important role of acidity of ripening grapes and its effect upon taste and quality of the wines, it has been found that total acidity correlates significantly with the acid taste in wines of Chenin blanc and Colombar for both FR and SC treatments (Table 5). The $\mathrm{pH}$ of the juice does not correlate as consistently with this aspect of wine quality as total acidity; in contrast to Chenin blanc, there was no significant correlation with wine taste in Colombar. From these few data it would appear that, at least as far as acid taste in wine is concerned, the total acidity would be a better guide than $\mathrm{pH}$. This finding agrees in general with that of Plane, Mattick \& Weirs (1980).

TABLE 5

Linear correlation coefficients of the relationship between the acceptability of the acid taste of wine with the juice total acidity and juice $\mathrm{pH}$ of Chenin blanc and Colombar grapes harvested at different maturities.

\begin{tabular}{llc}
\hline & \multicolumn{2}{c}{ Correlation of acid taste of wine with: } \\
\cline { 2 - 3 } $\begin{array}{l}\text { Cultivar/ } \\
\text { Treatment }\end{array}$ & Juice total acidity & Juice $\mathrm{pH}$ \\
\hline Colombar & & \\
FR $(n=33)$ & $-0,853^{* * *}$ & $0,067 \mathrm{~ns}$ \\
SC $(n=28)$ & $-0,488^{* *}$ & $-0,033 \mathrm{~ns}$ \\
Chenin blanc & & \\
FR $(n=28)$ & $-0,699^{* * *}$ & $0,678^{* * *}$ \\
SC $(n=22)$ & $-0,770^{* * *}$ & $0,543^{* *}$ \\
\hline
\end{tabular}

FR: Free run treatment

SC: Skin contact treatment

ns : Not significant

** : Significant at 99 percent confidence level

$* * *$ : Significant at 99,9 percent confidence level

$\mathrm{n}$ : Number of samples 
The effect of SC treatment on the relationship between wine quality and maturity index in grapes is illustrated in Fig. 4 and indicates earlier quality maxima for SC. The data in Table 3 show that for Chenin blanc the maximum quality occurred at a ${ }^{\circ} \mathrm{B} / \mathrm{TA}$ value of 2,4 , which is earlier and lower than the corresponding value for FR treatment, viz. approximately 2,8 . In the case of Colombar the FR treatment maximum quality occurs at a ${ }^{\circ} \mathrm{B} / \mathrm{TA}$ value of approximately 2,3 with the SC optimum not as clear as that of the FR (See Fig. 4).

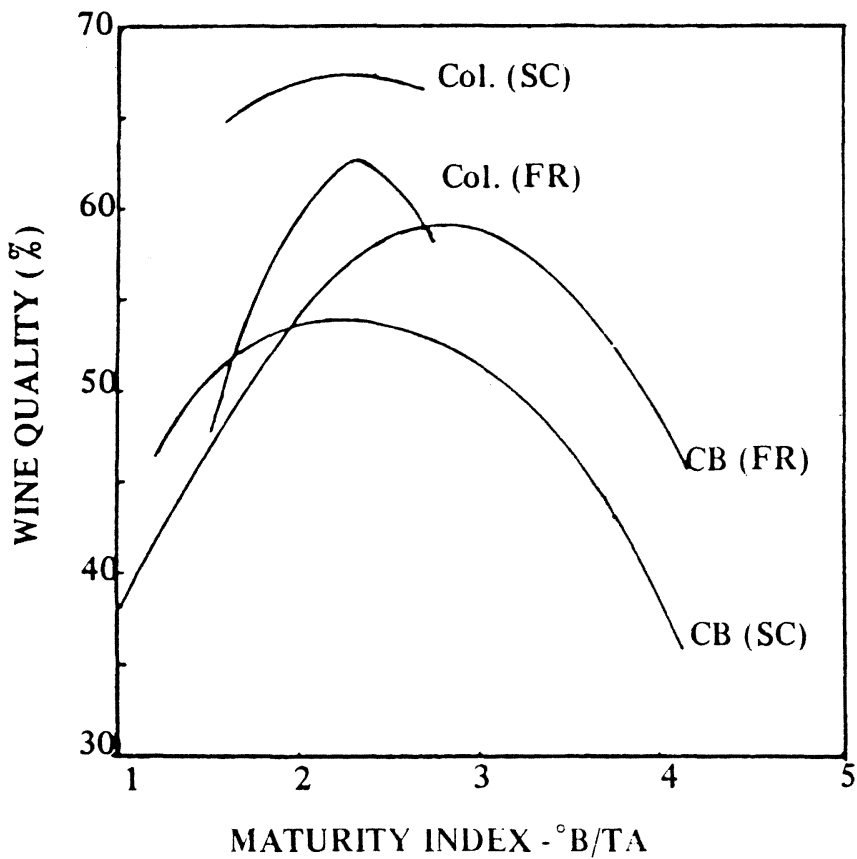

Fig. 4

Fitted curves relating wine quality and grape maturity index ${ }^{\circ} \mathrm{B} / \mathrm{TA}$ for Chenin blanc (CB) and Colombar (Col.) data for free run (FR) and skin contact (SC) treatments for six seasons.

Red cultivars: Relevant data are given in Tables 2, 3, 4 and Fig. 5. Significant relationships between wine quality and several grape maturity indices are given for Cabernet Sauvignon and Pinotage. Fitted curves for the ${ }^{\circ} \mathrm{B} / \mathrm{TA}$ index is given in Fig. 5 and indicate that optimum maturity occurs at approximately equal ${ }^{\circ} \mathrm{B} / \mathrm{TA}$ values, viz. 3,9 (See Table 3). As in the case of the white cultivars it was not possible to predict what the actual wine quality value at optimum grape maturity would be. Trends similar to that shown in Fig. 1 were obtained.

\section{SUMMARY AND CONCLUSIONS}

Curvilinear relationships between certain grape maturity indices have been established enabling calculation of optimum maturity values. The relative ease and speed with which an index like ${ }^{\circ} \mathrm{B} / \mathrm{TA}$ can be determined makes it eminently suitable to replace one like eg. total soluble solids which has not given satisfactory results in the past. Although the stage of optimum grape maturity could be determined relatively successfully, it was not possible to predict from these data what the actual level of optimum wine quality would be.

The stage of maturity of grapes has been shown to be a most important factor in the quality of the wine. Con-

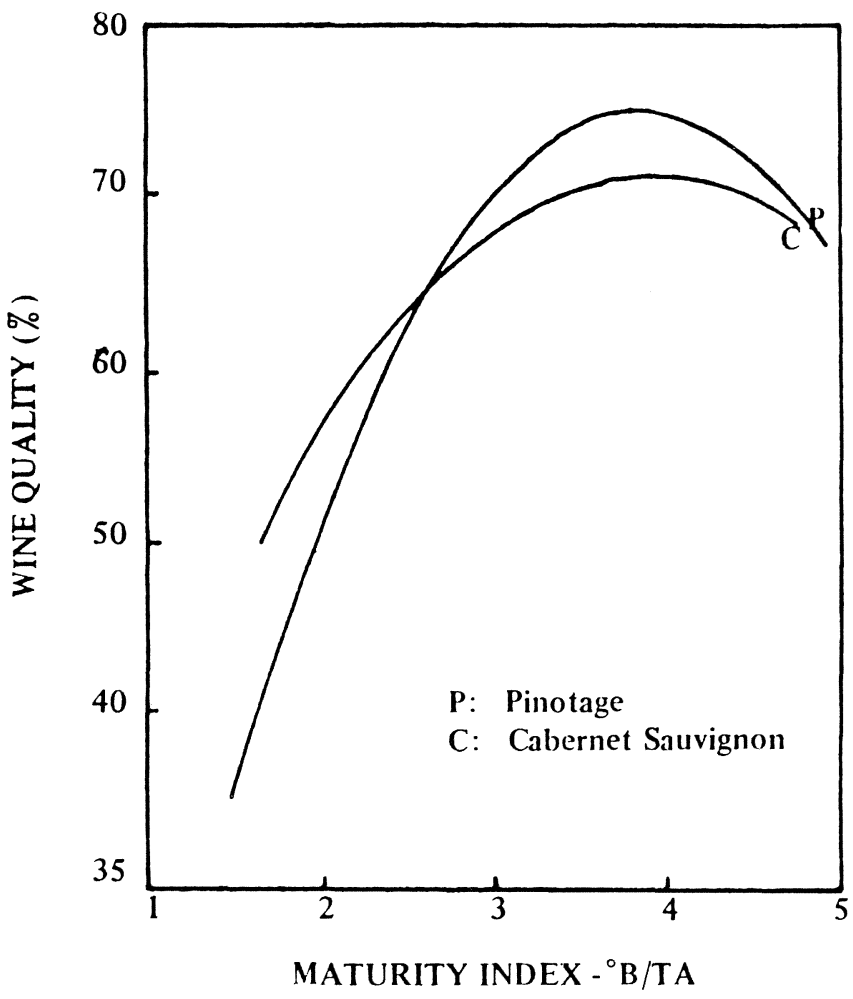

Fig. 5

Fitted curves relating wine quality and grape maturity index ${ }^{\circ} \mathrm{B} / \mathrm{TA}$ for Pinotage and Cabernet Sauvignon for five seasons.

sequently, when investigating factors other than grape maturity upon wine quality, it is imperative that grapes in such studies be harvested at optimum maturity to achieve meaningful results.

Skin contact treatment for especially Colombar, has the tendency to facilitate earlier harvesting. This practice could be useful under adverse weather conditions, possibly reducing peak grape intakes and also for treatment of grapes which were harvested too soon.

It has been shown that two cultivars from different regions differed appreciably with respect to the value of the ${ }^{\circ} \mathrm{B} / \mathrm{TA}$ index for optimum maturity. Furthermore, it was found that $\mathrm{pH}$ of the grape correlates with the acid taste in the wine of Chenin blanc, whereas this is not the case with Colombar. When skin contact was applied the hedonic acid taste was improved in Robertson Colombar but not in Stellenbosch Chenin blanc and during ripening of grapes considerably more fluctuation occurred in the total acidity and $\mathrm{pH}$ values of Colombar than in Chenin blanc. These four differences of possibly cultivar and/or environmental effects indicate that it is advisable to investigate the effect of ripening of grapes on wine quality in order to determine optimum maturity under own specific conditions.

\section{LITERATURE CITED}

AMERINE, M. A. \& WINKLER, A. J., 1941. Maturity studies with California grapes. I The Balling-acid ratio of wine grapes. Proc. Am. Soc. Hort. Sci. 38, $379-387$.

BERG, H. W., 1958. Better grapes for wine. Nature of the problem. Am. J. Enol. 9, 203 - 204. 
COOMBE, B. G., DUNDON, R. J. \& SHORT, A. W. S., 1980. Indices of sugar-acidity as ripeness criteria for winegrapes. J. Sci. Food. Agric. 31, 495 - 502.

COOKE, C. M., 1964. Effect of grape pulp upon soluble solids determinations. Am. J. Enol. Vitic. 15, 11 - 16.

DU PLESSIS, C. S., 1975. Fermentation formed components in relation to wine quality. Proc. 4th Int. Enological Symp. pp. 374 - 390. Valencia. Spain.

DU PLESSIS, C. S., 1976. Harvesting stage of Steen grapes in the Stellenbosch area. Bull. H7. Farm. in South Africa. Dept. Agric. Tech. Serv.

DU PLESSIS, C. S., 1977. Grape components in relation to white wine quality. Proc. Int. Symp. on the Quality of the Vintage pp. 117 - 128. Cape Town, South Africa.

KOURAKOU, S., 1974. Optimaler Reifegrad der Trauben in Bezug auf den Gewünschten Weintyp. Paper delivered XIV Congrés International de la Vigne et du Vin. Bolzano-Trento. Italy.

OUGH, C. S. \& ALLEY, C. J., 1970. Effect of Thompson Seedless grape maturity on wine composition and quality. Am. J. Enol. Vitic. 20, 78 - 84 .
OUGH, C. S. \& SINGLETON, V. L., 1968. Wine quality predictions from juice ${ }^{\circ} \mathrm{Brix} /$ acid ratio and associated compositional changes for White Riesling and Cabernet Sauvignon. Am. J. Enol. Vitic. 19, 129 138.

PLANE, R. A., MATTICK, L. R. \& WEIRS, L. D. 1980. An acidity index for the taste of wines. Am. J. Enol. Vitic. 31, $265-268$.

REUTLINGER, H., 1973. Wine making with the object of producing fruity wines. Paper delivered Third Int. Enolgical Symp. Cape of Good Hope. South Africa, 6- 10 March.

SINTON, T. H., OUGH, C. S., KISSLER, J. J. \& KASIMATIS, A. N., 1978. Grape juice indicators for prediction of potential wine quality. I. Relationship between crop level, juice and wine composition, and wine sensory ratings and scores. Am. J. Enol. Vitic. 29, $267-271$.

TROMP, A. \& CONRADIE, W. J., 1979. An effective scoring system for the sensory evaluation of experimental wines. Am. J. Enol. Vitic. 30, 278 - 283. 